\title{
EFFECT OF FIBER REINFORCEMENT ON FRACTURE RESISTANCE AND FRACTURE TOUGHNESS FOR LONG SPAN PROVISIONAL RESTORATIONS
}

\author{
Ziad H. Rabie *
}

\begin{abstract}
Aim of the work: This study was aimed to determine the effect of fiber reinforcement on the fracture load and toughness of long span provisional restorations.

Materials and method: Two types of commercially available provisional materials were selected Protemp ${ }^{\text {TM }} 4$ and Structur3. Two mechanical tests were performed to evaluate the fracture load and fracture toughness for each material. Twenty samples of four units, fixed partial dentures were fabricated to evaluate the fracture loading of both materials. The samples of each group were further subdivided into two equal subgroups (10 samples each). The first subgroup served as control, without fiber reinforcement while, the second subgroup included the addition of ultrahigh modulus polyethylene fibers (UHMPE) which is delivered pre-impregnated by the manufacturer. An electronic scale were used to pre-weight the fibers, then cut to a predetermined length $(2.0 \mathrm{~mm})$ before incorporation in the resin mix to represent $3 \%$ weight of the control sample. For fracture toughness test, twenty rectangular samples $(2.5 \times 5 \times 25 \mathrm{~mm})$ from each material were fabricated. Ten samples for each subgroup were used with and without addition of the fibers. The samples were soaked before testing in artificial saliva for 14 days and then were thermocycled for 2500 cycles between $5^{\circ} \mathrm{C}$ and $55^{\circ} \mathrm{C}$.
\end{abstract}

Conclusions: Structur3 provisional material showed higher fracture load and fracture toughness mean values than Protemp ${ }^{\mathrm{TM}} 4$.

Fiber impregnation into provisional restorations enhanced the fracture load significantly but did not show the same improvement with the fracture toughness.

KEY WORDS: Fiber reinforcement, Fracture load, Ffracture toughness, Provisional restorations

* Lecturer of Fixed Prosthodontics Faculty of Dentistry October 6 University 


\section{INTRODUCTION}

Provisional restorations are integral part of the treatment planning process and their integrity must be maintained throughout the diagnosis and restorative procedures. Clinical success of these restorations varied according to the type of the material used and the method of fabrication. ${ }^{[1]}$ Generally, when these materials are used in long span fixed partial dentures, they exhibit low fracture strengths.

The fracture related properties, such as fracture resistance, deformation under occlusal load, and the marginal degradation of materials have usually been evaluated by the determination of the basic material parameters of fracture strength and fracture toughness . [2]

Fracture toughness is a mechanical property that describes the resistance of brittle materials to the catastrophic propagation of pre-existing cracks or flaws under an applied load, and thus, it describes damage tolerance of the material and can be seen as a measure of fatigue resistance.

Fracture toughness values are dependent on physical properties and chemical composition of the individual component of restorative material. From a biomimetic point of view, we strive to replace lost tooth tissue by biomaterials with similar physical properties, especially with of flexural strength, modulus and thermal expansion coefficient. ${ }^{[3]}$

Fracture resistance of provisional restoration is an important clinical concern as the failure of the provisional prosthesis may cause great inconvenience for both patient and clinician. Failure often occurs suddenly as a result of crack propagation from a surface flaw. The strength and serviceability of any acrylic resin restoration, is determined by the material's resistance to crack propagation..$^{[4,5]}$

Attempts for reinforcing dental polymers using several types of fibers, have been made in order to increase the fracture resistance of temporary fixed partial dentures. Previous studies have tested the addition of polyethylene, carbon (graphite) fibers, or glass fibers into acrylic resin. Investigations have shown that carbon fibers produced a significant increase in the flexural strength of polymers, ${ }^{[6]}$ however, their dark color limits their use in esthetic restorations. ${ }^{[4]}$ Glass fibers are difficult to handle due to their spreading in undesired areas. ${ }^{[7]}$

Moreover, some authors reported that if the glass fibers protrude from the interim prostheses, the restorations may be difficult to polish and thus attract bacteria, causing irritation. ${ }^{[1,4,8]}$ Silanized glass fibers are highly recommended due to their good adhesion to the polymer matrix, high esthetic quality and increased strength of the resulting composite. ${ }^{[7,9]}$ The untreated polyethylene fibers did not show any improvement of transverse strength due to poor adhesion between the fibers and the polymer matrix, while plasma treated polyethylene fibers showed a significant increase in strength. ${ }^{[10,11]}$

Nohrstrom et al in 2000, analyzed the influence of the position and quantity of fibers on the fracture resistance of provisional FPD using unindirectional and woven glass fiber reinforcements. They concluded that the reinforcing effect of glass fibers become more evident in long span bridges. ${ }^{[12]}$

Dyer et al in 2004, found that, the highest fracture resistance value resulted from two unidirectional glass fiber reinforcements, one located on the tension side and the second on the compression side. ${ }^{[13]}$

Hamza et al in 2004, stated that, the surface treatment of fibers greatly influenced their effect on the fracture toughness and flexural strength of provisional resin restorations. ${ }^{[14]}$

Fahmy and Sharawy in 2009, assessed the efficiency of reinforcing provisional restorations by adding a fine metallic mesh or polyethylene fibers between the abutments spanning the pontic length. They stated that fiber and mesh reinforcements may alter the flexural strength and modulus of some, but not all provisional resins. ${ }^{[15]}$ 
Chen et al in 2009, determined the fracture load of long-span fiber-reinforced acrylic resin provisional FPDs using two types of fibers. They investigated the influences of fiber length and location on the fracture load after thermocycling. They concluded that fiber reinforcement enhanced the fracture load of long-span acrylic resin provisional FPDs. The weakest location was the tension side between the pontics. They recommended that the location of fiber strengthening was much more important than the length of reinforcement or fiber type. ${ }^{[16]}$

Kamble et al in 2012, compared the flexural strength of polymethyl methacrylate (PMMA) and bis-acryl composite resin reinforced with polyethylene and glass fibers. They found that, glass fiber reinforcement produced highest flexural strength. ${ }^{[17]}$

Anil et al in 2018, stated that multi-scale fillers such as carbon nano-fibers (CNFs) and short carbon fibers (SCFs) can significantly improve the fracture toughness of epoxy composites by various toughening mechanisms. A comparative assessment on the toughening performance promoted by fibers is presented along with the effects of aligning the filler normal to the crack growth using an applied alternating current (AC) electric field. For SCF concentrations of up to $1.5 \mathrm{wt} \%$, with a concentration of CNFs of $1.0 \mathrm{wt} \%$, the multi-scale, hybrid reinforcements additively toughen the epoxy polymer, with the measured fracture toughness being up to about fourteen times the value of the unmodified epoxy polymer. ${ }^{[18]}$

Fiber orientation has an influence on the strength, modulus and coefficient of thermal expansion, as it can change the fiber-reinforced polymer properties from isotropic to anisotropic and even orthotropic. ${ }^{[19]}$
Fracture of provisional restorations is of concern, especially with more extensive provisional restorations that must be used for longer periods of time, long-span fixed partial dentures or areas of heavy occlusal stress.

The purpose of this study was to compare the fracture load and fracture toughness of two different biasacryl provisional fixed restorative materials with reinforcing polyethylene fibers.

The null hypothesis of this study was that addition of pre-impregnated (UHMPE) fibers to the resin composites (structur3 and Protemp ${ }^{\mathrm{TM}} 4$ ) would increase the fracture loading and toughness of both provisional materials.

\section{MATERIALS AND METHOD}

Two types of commercially current provisional materials were selected, Protemp $\mathrm{p}^{\mathrm{TM}} 4$ and structur3. Table (1).

Twenty samples were fabricated from each material for each test, divided into two subgroups; 10 samples served as control, without fiber reinforcement and 10 samples with the addition of fibers to resin materials.

Pre-impregnated ultrahigh modulus polyethylene fibers (UHMPE) DVA Reinforced polyethylene fiber, California, USA, were supplied readily silanized with methacryloxypropyl-trimethoxy silane by the manufacturer to improve the adhesion between the fibers and resin materials.

The fibers were pre-weighed using an electronic scale, and cut to a predetermined length $(2.0 \mathrm{~mm})$ before incorporation in the resin mix. The fibers represented 3\% weight of the control sample. Two sample designs were selected according to the requirements of testing: Twenty samples of 4 unit fixed partial dentures for fracture load test, and twenty rectangular samples for fracture toughness test. 
TABLE (1): Structur 3 and Protemp 4 provisional materials composition

\begin{tabular}{|c|c|l|c|}
\hline Material & Manufacturer & Composition* & Filler content \%wt \\
\hline Structur 3 & $\begin{array}{c}\text { VOCO GmbH, } \\
\text { Cuxhaven, Germany }\end{array}$ & $\begin{array}{l}\text { Catalyst: (Urethanedimethacrylate, Bis GMA, benzoyl peroxyde); } \\
\text { Base: (Urethanedimethacrylate) }\end{array}$ & $35 \%$ \\
\hline Protemp 4 & $\begin{array}{c}\text { 3M ESPE, } \\
\text { St. Paul. Minnesota, } \\
\text { USA }\end{array}$ & $\begin{array}{l}\text { Catalyst: (2,2'-[(1-methylethylidene) bis (4,1 phenyleneoxy)] } \\
\text { bisethydiacetate, benzyl- phenyl-barbituric acid, silane treated } \\
\text { silica, Tert-butyl 3,5,5-trimethylperoxyhexanoate); } \\
\text { Base: (Dimethacrylate (bisema6), silane treated amorphous } \\
\text { sílica, reaction products of 1,6-diisocyanatohexane with } \\
\text { 2-[(2-metacryloyl)ethyl]6-hydroxyhexanoate and 2-hydroxyethyl } \\
\text { methacrylate (desma), silane treated silica) }\end{array}$ & $32 \%$ \\
\hline
\end{tabular}

Information provided by manufacturer

\section{Fracture load testing:}

Two stainless steel non-anatomic dies representing a first premolar $(6 \mathrm{~mm}$ in height , $3 \mathrm{~mm}$ occlusal diameter and $4 \mathrm{~mm}$ cervical diameter) and a second molar $(6 \mathrm{~mm}$ in height , $6 \mathrm{~mm}$ occlusal diameter and $7.5 \mathrm{~mm}$ cervical diameter) teeth were fabricated and set at $18 \mathrm{~mm}$ apart in a specially designed metal assembly provided with 2 slots. A four-unit $\mathrm{Co}-\mathrm{Cr}$ FPD was cast to fit over the dies. two non-anatomical copings to fit over the two stainless steel dies having $1 \mathrm{~mm}$ axial wall thickness and $1.5 \mathrm{~mm}$ occlusal thickness, two pontics representing a second premolar $(5 \mathrm{~mm}$ width, $4 \mathrm{~mm}$ occlusogingivally and $2.5 \mathrm{~mm}$ buccolingual depth) and a first molar $(8 \mathrm{~mm}$ width, $4 \mathrm{~mm}$ occlusogingivally and $2.5 \mathrm{~mm}$ buccolingual depth), and three connectors having $4 \mathrm{~mm}$ occlusogingival height, $2 \mathrm{~mm}$ mesiodistal width, and $2 \mathrm{~mm}$ buccolingual width.

Then, elastomeric putty impression material (Speedex Putty, Coltene Whaledent-Switzerland) was used with a special stainless steel tray to obtain twenty equal molds which served for the construction of the provisional FPDs.

The control group of FPDs were constructed by filling the mold with resin using a special plastic syringe supplied by the manufacturer to minimize porosity. For the reinforced samples fabrication, the cut and pre-weighed polyethylene fibers were added to the resin materials and hand-mixed. To facilitate packing, $2 \mathrm{~mm}$ of the syringe tip was cut to allow easy extrusion of the fiber-reinforced resin.

The mixed reinforced resin was loaded inside the mold which was seated on the metal dies. A glass slab was placed over the assembly until final setting to ensure constant pressure. Twenty high-strength epoxy resin (Kemapoxy165, Egypt) models were duplicated. After setting, each sample was cemented on its epoxy model with the temporary eugenolfree cement. (Temp Bond ${ }^{\mathrm{TM}}$, Kerr Corp, Orange, CA, USA).

The samples were soaked before testing in artificial saliva for 14 days and then were thermocycled for 2500 cycles between $5^{\circ} \mathrm{C}$ and $55^{\circ} \mathrm{C}$.

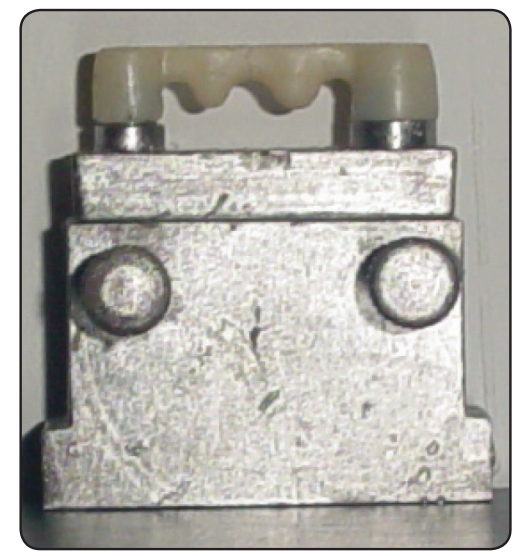

Fig. (1) Construction of provisional F.P.D for fracture resistance testing 
Each sample on its epoxy model was secured to the lower fixed compartment of a computer controlled testing machine with a load cell of $5 \mathrm{kN}$. The loading stamp (5.7mm diameter) was centrally positioned over the occlusal surface of the pontic area. Each sample underwent pre-loading in a cyclic manner with 10000 cycles at loads between minimum $10 \mathrm{~N}$ and maximum $49 \mathrm{~N}$ with a load profile in the form of a sine wave at frequency of $1 \mathrm{~Hz}$. These values represent the average biting force.

The samples were then statically loaded under compression using the same computer controlled material testing machine until fracture at a crosshead speed of $0.5 \mathrm{~mm} / \mathrm{min}$ with the same load application.

The load-deflection curves were recorded with computer software. Failure was manifested by the first audible crack and confirmed by a sudden drop in the recorded load-deflection curve

The load required to fracture the sample was recorded in Newton.

\section{Fracture toughness testing}

A custom-made stainless steel mold was used to produce standardized single-edge notch sample for 3-point bending test to calculate the fracture toughness of the two selected provisional materials with and without fiber reinforcement.

The dimensions of the sample mold were (2.5 $\mathrm{mm} \times 5 \mathrm{~mm} \times 25 \mathrm{~mm}$ ). The depth of the pre-crack was $2.5 \mathrm{~mm}$, which was half the width of the sample. The samples were constructed by filling the mold with resin and placing it between two glass slabs.

Excess resin was removed before complete setting. The structur3 were left for 5 minutes while Protemp ${ }^{\mathrm{TM}} 4$ resin samples were left for 4 minutes to ensure complete polymerization according to the manufacturer's recommendations. The samples were soaked before testing in artificial saliva for 14 days and then were thermocycled for 2500 cycles between $5^{\circ} \mathrm{C}$ and $55^{\circ} \mathrm{C}$.

Fracture toughness was determined on a singleedge notch sample using the three-point bending method according to ASTM E399-90 (1996). ${ }^{[20]}$

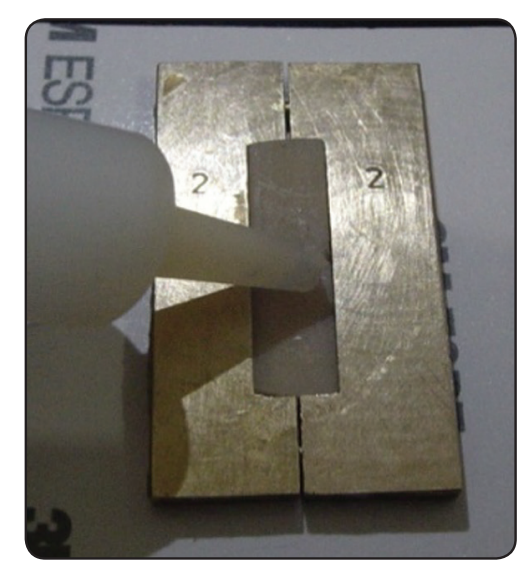

Fig. (2) Construction of single edge notch specimen for fracture toughness testing

The samples were placed on the supports of the 3-point loading apparatus. The span width of the supports was $20 \mathrm{~mm}$ with the notch centrally located on the tensile side. Mechanical loading was applied to the center of each sample at 90 degrees to the samples axis using a stainless steel rod attached to a computer controlled testing machine with a load cell of $5 \mathrm{kN}$ and data were recorded using computer software. (Model LRX-plus; Lloyd Instruments Ltd., Fareham, UK.)

The samples were then statically loaded in compressive mode until fracture at a crosshead speed of $0.5 \mathrm{~mm} / \mathrm{min}$. The load-deflection curves were recorded with computer software.** NexygenMT; Lloyd Instruments

\section{Calculation of fracture toughness by the single- edge notched method;}

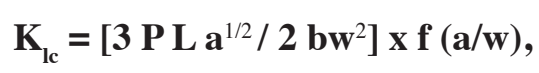

Where $\mathrm{P}=$ maximum load at fracture, $\mathrm{L}=$ distance between the supports, $b=$ samples width and $\mathrm{w}=$ samples height,

$\mathrm{P}=$ load at failure $\mathrm{L}=20 \mathrm{~mm} ; \mathrm{a}=2.5 \mathrm{~mm}$; $\mathrm{b}=2.5 \mathrm{~mm}$ and $\mathrm{w}=5 \mathrm{~mm}$

$$
\begin{aligned}
& \mathrm{f}(\mathrm{a} / \mathrm{w})=\left[1.93-3.07(\mathrm{a} / \mathrm{w})+14.53(\mathrm{a} / \mathrm{w})^{2}-25.11(\mathrm{a} /\right. \\
& \left.\mathrm{w})^{3}+25.80(\mathrm{a} / \mathrm{w})^{4}\right]
\end{aligned}
$$

The recorded data of the performed tests were collected and tabulated. 


\section{Statistical Analysis}

Data analysis was performed in several steps. Initially descriptive statistics for each group results. Two-way analysis of variance ANOVA test of significance comparing variables affecting mean values (material type and fiber reinforcement). Statistical analysis was performed using Assistat 7.6 statistics software for Windows (Campina Grande, Paraiba state, Brazil). $P$ values $\leq 0.05$ are considered to be statistically significant in all tests.

\section{Scanning Electron Microscope}

Scanning Electron Microscope (SEM) micrographs were taken from the random fractured surfaces of the four groups. Fractured surfaces were carefully cut from the FPD segments, stuck to samples holders. Scanning evaluation was performed with a scanning electron microscope.

\section{RESULTS}

Data analysis was performed in several steps. Initially, descriptive statistics for each group results. Two way analysis of variance ANOVA test of significance comparing variables affecting mean values (material and fiber reinforcement). Statistical analysis was performed using Asistat 7.6 statistics software for Windows (Campina Grande, Paraiba state, Brazil). $\mathrm{P}$ values $\leq 0.05$ are considered to be statistically significant in all tests.

\section{Fracture resistance (load)}

Descriptive statistics of the fracture resistance results measured in Newton for both groups with or without fiber reinforcement were presented in table (2) and graphically drawn in figure (3)

TABLE (2) Fracture resistance results for both groups before and after fiber-reinforcement

\begin{tabular}{|c|c|c|c|c|c|c|}
\hline \multirow{2}{*}{ Variables } & \multicolumn{2}{c|}{ Structur 3 } & \multicolumn{2}{c|}{ Protemp 4 } & Statistics \\
\cline { 3 - 8 } & Mean & SD & Mean & SD & P value \\
\hline \multirow{2}{*}{$\begin{array}{c}\text { Fiber } \\
\text { reinforcement }\end{array}$} & With & $246.1005^{\mathrm{A}}$ & 26.25541 & $223.0767_{\mathrm{a}}^{\mathrm{A}}$ & 3.176589 & $0.0781 \mathrm{~ns}$ \\
\cline { 2 - 8 } & Non & $177.9753^{\mathrm{B}}$ & 27.42737 & $128.4838_{\mathrm{a}}^{\mathrm{B}}$ & 2.345056 & $0.0364 *$ \\
\hline \multirow{2}{*}{ Statistics } & Pvalue & \multicolumn{2}{|c|}{$0.0401^{*}$} & \multicolumn{2}{|c|}{$0.0001^{*}$} & \\
\hline
\end{tabular}

significant $(p<0.05) \quad n s ;$ non-significant $(p>0.05)$

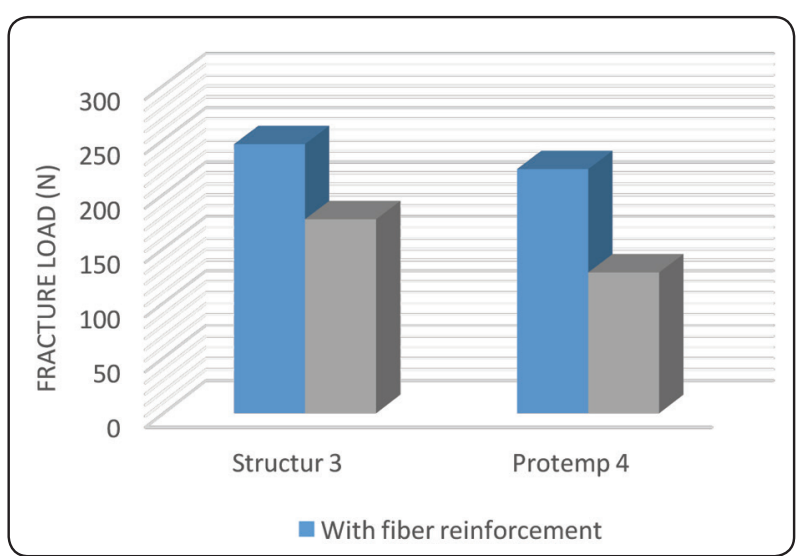

Fig. (3) Histogram of the fracture resistance mean values for both groups with or without fiber reinforcement

\section{Effect of material}

Regardless to fiber reinforcement, totally it was found that Structur3 group recorded statistically significant $(\mathrm{P}<0.05)$ higher fracture resistant mean value than Protemp4 group as indicated by two way ANOVA followed by pair-wise Tukey's posthoc tests 


\section{Effect of fiber reinforcement}

Regardless to material type, totally it was found that fiber reinforced subgroup recorded statistically significant $(\mathrm{P}<0.05)$ higher fracture resistant mean value than non-reinforced group as indicated by two way ANOVA followed by pair-wise Tukey's post-hoc tests

\section{Fracture toughness}

Descriptive statistics of the fracture toughness results measured in $\left(\mathrm{MPa} \cdot \mathrm{m}^{1 / 2}\right)$ for both groups with or without fiber reinforcement were presented in table (3) and graphically drawn in figure (4)

TABLE (3) Fracture toughness results for both groups before and after fiber-reinforcement

\begin{tabular}{|c|c|c|c|c|c|c|}
\hline \multirow{2}{*}{ Variables } & \multicolumn{2}{c|}{ Structur 3 } & \multicolumn{2}{c|}{ Protemp 4 } & Statistics \\
\cline { 3 - 7 } & Mean & SD & Mean & SD & P value \\
\hline \multirow{2}{*}{$\begin{array}{c}\text { Fiber } \\
\text { reinforcement }\end{array}$} & With & 1.394975 & 0.144715 & 1.36191 & 0.104986 & $0.7728 \mathrm{~ns}$ \\
\cline { 2 - 7 } & Non & 1.393325 & 0.042185 & 1.342107 & 0.069991 & $0.4351 \mathrm{~ns}$ \\
\hline Statistics & P value & \multicolumn{2}{|c|}{$0.4947 \mathrm{~ns}$} & \multicolumn{2}{|c|}{$0.0541 \mathrm{~ns}$} & \\
\hline
\end{tabular}

Significant $(p<0.05)$

ns; non-significant ( $p>0.05)$

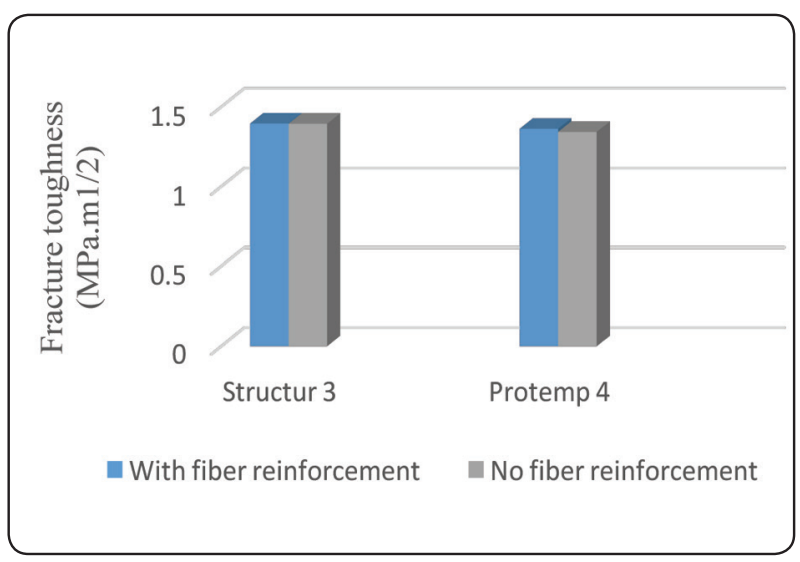

Fig. (4) Histogram of the fracture toughness mean values for both groups with or without fiber reinforcement

\section{Effect of material}

Regardless to fiber reinforcement, totally it was found that Structur3 group recorded statistically non-significant $(\mathrm{P}>0.05)$ higher fracture toughness mean value than Protemp4 group as indicated by two way ANOVA followed by pair-wise Tukey's post-hoc tests

\section{Effect of fiber reinforcement}

Regardless to material type, totally it was found that fiber-reinforced subgroup recorded statistically non-significant $(\mathrm{P}>0.05)$ higher fracture toughness mean value than non-reinforced group as indicated by two way ANOVA followed by pair-wise Tukey's post-hoc tests

\section{Scanning Electron Microscope results:}

Figures (5 \& 6) show Structur 3 and Protemp 4 containing Nano-filler particles within the resin matrix that are tightly embedded into the resin matrix resulting in a smooth fracture surface. Some voids were evident and an interface was seen between the fibers and the resin matrix. Generally the fibers did not separate from the matrix and were still closely interlocked with the resin matrix.

The fibers in both Structur 3 and Protemp 4 showed random (non-unidirectional) orientation in the mix. 


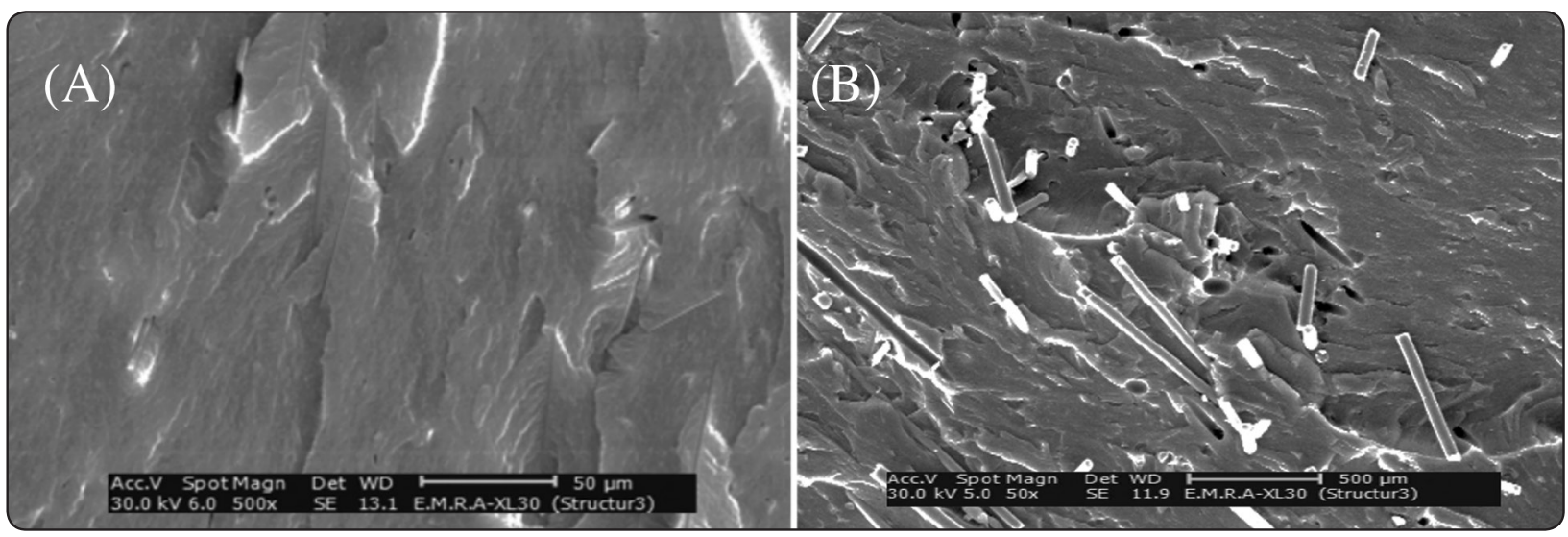

Fig. (5) SEM micrographs of Structur 3. a) Non-fiber reinforced. b) Fiber reinforced.

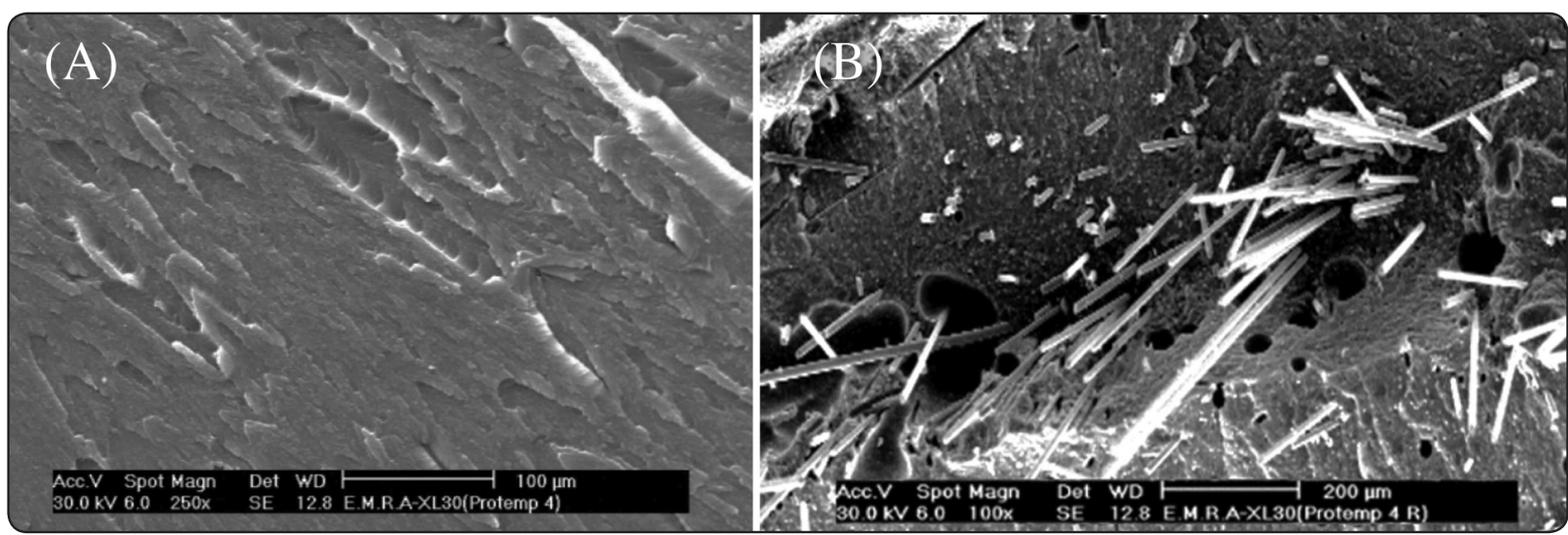

Fig. (6) SEM micrographs of Protemp 4. a) Non-fiber reinforced. b) Fiber reinforced.

\section{DISCUSSION}

The purpose of this study was to evaluate the effect of UHMPE pre-impregnated fibers on the fracture resistance and toughness of two resin provisional restorations.

A high modulus is necessary for fiber-reinforced restorations as it offers more support to brittle resins. ${ }^{[15]}$

Abdulrazzaq et al stated that when the resin is reinforced with rubbery particles which has lower elastic modulus and higher Poisson's ratio than the matrix, this creates polymer with lower elastic modulus and higher Poisson's ratio than the nonreinforced polymer ${ }^{[21]}$
The mechanical properties of fiber reinforced materials are dependent on the fiber type, length, archeticture, their ratio to the resin matrix and type of impregnation.

In order for fibers to act as an effective reinforcement for resins, stress transfer from the matrix to the fiber is essential. This is achieved by having a fiber length equal to or greater than the critical fiber length which could be as much as 50 times the diameter of the fiber, therefore, $2 \mathrm{~mm}$ length of fibers were incorporated within the resin materials. ${ }^{[3]}$

The fracture mechanics approach is considered a more reliable indicator of the performance of brittle materials. ${ }^{[22]}$ The clinical fracture resistance of 
FPDs is related to the size, shape, and position of the connectors and to the span of the pontic. Therefore, four unit provisional FPDs were constructed in this study to test the fracture resistance of a long span bridge (with and without the addition of fibers) as the bridge will flex more with increase in the pontic space mesiodistally based on the fact that, bending varies directly with the cube of length of the pontic. So, it was hypothesized that, the mean load at failure in the present study may differ than other studies due to difference in span length. ${ }^{[15,23]}$

Laboratory strength and toughness values under static loading does not reflect intraoral conditions; and failures of dental restorations are most often caused by fatigue fractures ${ }^{[24]}$ Cyclic loading therefore would be more reliable and might result in different results ${ }^{[25]}$

In the present study, all samples were stored in artificial saliva for 14 days to simulate artificial aging as described elsewhere. ${ }^{[26,27]}$

Alt et all, reported that the maximum force at fracture was affected by the storage condition for acomposite based temporary crown and bridges. In addition, the effect seems to be more pronounced, if the FPDs are fabricated directly. This effect might be explained by the water uptake of the materials, acting as a plasticizer. ${ }^{[28]}$

Mouth temperatures range between $-8^{\circ} \mathrm{C}$ and $+81^{\circ} \mathrm{C}$ and the resulting temperatures on the restoration surface between $5^{\circ} \mathrm{C}$ and $55 \mathrm{oC}$, therefore thermocycling is an essential step to mimic the clinical situation. ${ }^{[29]}$

A significant increase in the fracture resistance of Structur3 without addition of fiber reinforcements compared to Protemp ${ }^{\text {TM }} 4$ values was apparent in this study.

This could be explained by the composition of Structur3 which has been modified and marketed as nano-hybrid fumed silica (aerosil) in urethane dimethacrylate and etoxylated Bis-GMA which is cross linked - one at least double bond. This may be explained also by the higher filler content within the resin matrix of Structur 3.

On the other hand, the modifications of Protemp $\mathrm{P}^{\mathrm{TM}} 4$ included a newly developed monomer system Methylethylidene Bisdiacetate, with a somewhat flexible chain. ${ }^{[30]}$

Both materials are nano-sized which may explain the smooth surface fracture as shown in figures (5A and 6A)

Each material is thought to have physical properties unique to its chemistry.

The results showed numeric increase in mean fracture load and toughness values of the reinforced Structur3 and Protemp4 resins. (Tables 2 and 3) but this increase did not appear to be statistically significant for the fracture toughness results.

The basic requirement for reinforcing resins is an adequate bond as, in the case of an inadequate bond, the filler may act as an inclusion body and weaken the prosthesis..$^{[1,31]}$

The stronger the adhesion between the fiber and the matrix, the greater the strengthening effect. The stronger adhesion gained from the pre-impregnation with silane by the manufacturer.

The resin matrix forms a continuous phase that surrounds the fibers, thus the loads are transferred from the matrix to the fibers. The stiffness of the fibers is an important influence for strengthening brittle materials. Fibers impregnation is another factor affecting the strength of fiber reinforced

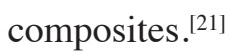

SEM in the present study showed adhesion between the fibers and matrix (figure 5B and 6B). But there were little areas showed clear boundaries between the fibers and the matrix at the fracture interface.

The polyethylene fibers produced a significantly higher fracture resistance for both resins. 
Many investigators who confirmed the reinforcing effect of fibers on different polymer types. ${ }^{[32-34]}$ The addition of fibers would make the reinforced resins develop higher rigidity, allowing less bending, thereby increasing its fracture strengths and toughness. These findings were in disagreement with other studies, stated that there is no significant increase in fracture resistance of the provisional resins with addition of fibers. ${ }^{[15,35-37]}$

A clear interface between the fibers and resin matrix in some areas on the fracture surface was observed by scanning electron microscope (Figures $5 \mathrm{~B}$ and $6 \mathrm{~B})$.

Water sorption might result in a detrimental hydrolytic effect. Furthermore, the polymerization shrinkage of the resin materials could cause a split between the fibers and the polymer matrix. Finally the result of the present study can also be explained by the fact that, a brittle material, has a higher compressive than tensile strength. Therefore, restorations fracture on the tension side away from the occlusal load. When the tensile strength of the polymer is lower than the tensile strength of the fiber, the sample will gain strength when the fiber is placed in the area of higher tension, away from the load. This was confirmed by Hamza et al. ${ }^{[14]}$

Fracture toughness is a mechanical property that describes the resistance of brittle materials to the catastrophic propagation of pre-existing cracks or flaws under an applied load, and thus, it describes damage tolerance of the material.

Fracture toughness values are dependent on physical properties and chemical composition of the individual component of restorative material. ${ }^{[3]}$

Several different sample geometries have been used to measure fracture toughness of dental materials. In this study fracture toughness was determined by a single-edge notch sample using the three-point loading bending method.

The pattern of failure for the reinforced restorations was totally different from the control group.
Instead of two separate segments, the reinforced restorations failed but remained attached.

The resins were toughened by the addition of short fibers. The fracture toughness values increased but non-significantly, this may attribute to many reasons.

The energy needed to fracture the specimens can be influenced by the fiber orientation, the embedded fiber length, the number of fibers that bridge the crack and the localized deformation around the fibers bridging the crack.

If the fibers are orientated randomly the mechanical properties are the same in all directions and the mechanical properties were isotropic. In the present study, the fibers were placed randomly with in the matrix as seen by SEM.

The embedded fiber length is the length of the shorter fiber segment intersected by the plane of the crack. Assuming that the fracture plane has equal probability to intersect the fiber at any location along its length, the embedded fiber length is estimated to be $1 / 4$ the fiber length. ${ }^{[38]}$

Toughening by fibers addition occurs through three mechanisms within the crack zone; fiber pullout, fiber breakage and fiber-matrix debonding. Fiber pull-out or fiber breakage occurs for fibers bridging the crack. Fiber pull-out occurs for fibers that are nearly perpendicular to the fracture plane or have one end embedded into the matrix. Fiber breakage occurs for fibers bridging the crack at oblique angles and has both ends embedded into the matrix in length more than the fiber diameter. Fibermatrix debonding occurs for fibers sufficiently close to the crack plane. ${ }^{[38]}$

Norman and Robertson stated that, fibers that pull out from the matrix at oblique angles are bent into S-shape, which leads to bending moment along the fiber. This may lead to fiber breakage if its flexural strength is exceeded. 
Fiber bending during pull out leads to increased friction of the fiber within the matrix.

Bending of the fibers is accompanied by localized deformation of the matrix leading to matrix yielding. ${ }^{[38]}$

In this study finding out that the fracture resistance for both fiber-reinforced resins increased significantly while the fracture toughness increased non-significantly may be attributed to that not all the amount of the fibers that were added to the matrix, have performed the function of bridging the crack.

Using the materials in a clinically simulating form (long span bridge) gave better results than using the same materials in rectangular (non-clinically imitating) form.

\section{CONCLUSION}

Within the limitations of this study, the following conclusions were drawn: For the two types of samples, although the result didn't shown a significant increase in the fracture toughness values of the reinforced resin, the reinforcement material prevented complete separation of the fractured parts and held the fragments together.

Clinically, when using long span provisional restorations for a long and extended period, it is recommended to use impregnated fibers to reinforce the restorations. This might prevent catastrophic failure and may decrease patient discomfort and unscheduled appointments, suggesting that use of these fibers may be beneficial in reinforcing fixed provisional restorations.

\section{REFERENCES}

1. Gratton DG, and Aquilino SA: Interim restorations. Dent Clin North Am. 2004; 48: 487-97.

2. van Dijken JW, Lindberg A. A 15-years randomized controlled study of a reduced shrinkage stress resin composite. Dent Mater. 2015; 31: 1150-58.

3. Lippo Lassila, Filip Keulemans, Eija Sailynoja and Pekka K. Vallittu. Mechanical properties and fracture behavior of flowable fiber reinforced composite restorations. Dent Mater. 2018; 34: 598-606.

4. Larson WR, Dixon DL, Aquilino SA, and Clancy JM. The effect of carbon graphite fiber reinforcement on the strength of provisional crown and fixed partial denture resins. J Prosthet Dent. 1991; 66: 816-20.

5. Gegauff AG, and Wilkerson JJ. Fracture toughness testing of visible light and chemical-initiated provisional restoration resin. Int J Prosthodont. 1995; 8: 62-68.

6. Vallittu PK. High- aspect ratio fillers: fiber-reinforced composites ad their anisotropic properties. Dent Mater. 2015; 31: 1-7.

7. Aydin C, Yilmaz H, and Caglar A. Effect of glass fiber reinforcement on the flexural strength of denture base resin. Quintessence Int. 2002; 33:457-63.

8. Yazdanie N, and Mahood M. Carbon fiber acrylic resin composite: an investigation of transverse strength. J Prosthet Dent. 1985; 54:543-7.

9. Solnit GS. The effect of methyl methacrylate reinforcements with silane treated and untreated glass fibers. J Prosthet Dent. 1991; 66:310-314.

10. Vallittu PK. Ultra-high-modulus polyethylene ribbon as reinforcement for denture polymethyl methacrylate: a short communication. Dent Mater. 1997; 13(6):381-2.

11. Ramos V Jr, Runyan DA, and Christensen LC. The effect of plasma treated polyethylene fiber on the fracture strength of polymethyl methacrylate. J Prosthet Dent. 1996; 76:94-6.

12. Nohstorn TJ, Vallittu PK, and Uli-Urpo A. The effect of placement and quantity of glass fibers on the fracture resistance of interim fixed partial denture dentures. Int J Prosthodont. 2000; 13:72-8.

13. Dyer SR, Lassila LVJ, Jokinen M, and Vallittu PK. Effect of fiber position and orientation on fracture load of fiberreinforced composite. Dent Mater 2004; 20:947-55.

14. Hamza TA, Rosenstiel S F, Elhosary M M, and Ibraheem $\mathrm{R} M$. The effect of fiber reinforcement on the fracture toughness and flexural strength of provisional restorative resins. J Prosthet Dent. 2004; 91:258-64.

15. Fahmy N Z, and Sharawy A. Effect of Two Methods of Reinforcement on the Fracture Strength of Interim Fixed Partial Dentures. J Prosthodont. 2009; 18: 512-20.

16. Chen W, Hung C, Huang Y, Wang C, and Wang G. Fracture load of provisional fixed partial dentures with longspan fiber-reinforced acrylic resin and thermocycling. J Dent Sci. 2009; 4(1):25-31. 
17. Kamble VD, Parkhedkhar RD and Mowade TK. The effect of different fiber reinforcements on flexural strength of provisional restorative resins: an in-vitro study. J Adv Prosthodont. 2012; 4(1): 1-6.

18. Anil R. Ravindran, Raj B.Ladani, ShuyingWu, Anthony J.Kinloch, Chun H. Wang, Adrian P. Mouritz. Multiscale toughening of epoxy composites via electric field alignment of carbon nanofibres and short carbon fibres. Composites Science and Technology. 2018; 167:115-125.

19. Ankit Kumar, Shweta Tekriwal, B. Rajkumar, Vishesh Gupta, and Radhika Rastogi. A review on fibre reinforced composite resins. Annals of Prosthodontics and Restorative Dentistry. 2016; 2(1):11-16.

20. Akihiro Fujishima, Jack L. and Ferracane. Comparison of four modes of fracture toughness testing for dental composites. Dent Mater. 1996; 12: 38-44.

21. Abdulrazzaq N S, Jafarzadeh K T, Behroozibakhsh M, Hajizamani $\mathrm{H}$ and Habibzadeh S. recent advances and future perspective for reinforcement of poly(methyl methacrylate) denture base materials; A literature review. J Dent Biomater. 2018; 5(1): 490-502.

22. Gegauff AG, and Pryor HG. Fracture toughness of provisional resins for fixed prosthodontics. J Prosthet Dent. 1987; 58: 23-9.

23. Shi L, and Fok A S L. Structural optimization of the fibrereinforced composite substructure in a three-unit dental bridge. Dent Mater. 2009; 25:791-801.

24. Torbjorner, A. and Fransson, B. A literature review on the prosthetic treatment of structurally compromised teeth. Int J Prosthodont. 2004; 17: 369-76.

25. Fokkinga W A, Kreulen C M, Le Bell-Rönnlöf AM, Lassila LV, Vallittu P K and Creugers N H. Fracture behavior of structurally compromised non-vital maxillary premolars restored using experimental fiber reinforced composite crowns. Am J Dent. 2006; 19:326-32.

26. Pfeiffer $\mathrm{P}$, and Grube L. In vitro resistance of reinforced interim fixed partial denture. J Prosthet Dent. 2002; $87: 225-8$
27. Lang R, Rosentritt M, Behr M, and Handel G. Fracture resistance of PMMA and resin matrix composite-based interim FPD materials. Int J Prosthodont. 2003; 16: 381-4.

28. Alt V, Hannig M, Wostmann B and Balkenhol M. Fracture strength of temporary fixed partial dentures: CAD/CAM versus directly fabricated restorations. Dent Mater. 2011; 27:339-47.

29. Farahnaz Nejatidanesh, Glareh Momeni \& Omid Savabi. Flexural Strength of Interim Resin Materials for Fixed Prosthodontics. Journal of Prosthodontics. 2009; 18: 507-511.

30. Keulemans P P, Aboushelib M M N , Dalen AV, Kleverlaan $\mathrm{C} \mathrm{J}$ and Feilzer A J. Fracture strength and fatigue resistance of dental resin-based composites. Dent Mater. 2009; 25:1433-41.

31. Chung K, Lin T, and Wang F: Flexural strength of a provisional resin material with fiber addition. J Oral Rehabil. 1998; 25:214-17.

32. Goldberg A J and Burstone $\mathrm{C} \mathrm{J}$. The use of continuous fiber reinforcement in dentistry. Dent. Mater. 1992; 8:197-202.

33. Osman Y I and Owen C P. Flexural strength of provisional restorative materials. J Prosthet Dent. 1993; 70: 94-96.

34. Vallittu P K. The effect of glass fiber reinforcement on the fracture resistance of a provisional fixed partial denture. J Prosthet Dent. 1998; 79:125

35. Braden M, Davy KW and Parker S. Denture base poly (methyl) methacylates reinforced with ultra-thin modulus polyethylene fibers. Br Dent J. 1988; 164:109-113.

36. Samadzadeh A, Kugel G, Hurley E and Aboushala A. Fracture strength provisional restorations restored with plasma-treated woven polyethylene fiber. J Prosthet Dent. 1997; 78:447-50.

37. Geerts G, Overturf $\mathrm{J}$ and Oberholzer T. The effect of different reinforcements on the fracture toughness of materials for interim restorations. J Prosthet Dent. 2008; 99:461-7.

38. Norman D A, Robertson R E. The effect of fiber orientation on the toughening of short fiber-reinforced polymers. J Appl Polym Sci. 2003; 90: 2470-2751. 